\title{
Goal-directed therapy in cancer surgery: a randomised and controlled trial (GRICS II)
}

\author{
A Gerent ${ }^{1 *}$, JP Almeida ${ }^{1}$, F Galas ${ }^{1}$, JT Fukushima ${ }^{1}$, E Osawa ${ }^{1}$, C Park¹, R Franco ${ }^{1}$, Y Sakr ${ }^{2}$, LA Hajjar $^{1}$ \\ From ESICM LIVES 2015 \\ Berlin, Germany. 3-7 October 2015
}

\section{Introduction}

A perioperative hemodynamic goal-directed therapy (GDT) has been advocated in patients undergoing high risk-surgery in order to reduce postoperative complications. Nevertheless, the benefits of GDT in surgical patients are controversial and may lead to an overuse of fluids, inotropic agents and blood transfusion.

\section{Objectives}

The aim of this randomized, controlled, single-center trial was to assess the effect of GDT after abdominal oncology surgery on the incidence of major postoperative complications. We also evaluated the requirements of fluid, inotropic agents, blood transfusion and the intensive care unit (ICU) and hospital length of stay between groups.

\section{Methods}

We randomly assigned patients admitted to the ICU after major abdominal oncology surgery to receive either GDT protocol or usual care. The GDT protocol involved hemodynamic optimization aimed at a target of a cardiac index $>2.5 \mathrm{~L} /$ minute $/ \mathrm{m} 2$ (by minimally invasive cardiac output monitoring) and a mean arterial pressure of $70 \mathrm{mmHg}$ through a three-step approach: fluid therapy of $250 \mathrm{ml}$ albumin $4 \%$ in lactated Ringer's solution, dobutamine infusion up to a dose of $20 \mu \mathrm{g} / \mathrm{kg} /$ minute, and red blood cell transfusion to reach a hemoglobin level above $8 \mathrm{~g} / \mathrm{dL}$. The primary outcome was a 30 -day composite endpoint of acute kidney injury, major cardiovascular complications, adult respiratory distress syndrome, septic shock, reoperation and mortality.

${ }^{1}$ Instituto do Câncer do Estado de São Paulo, Anesthesia and Critical Care, São Paulo, Brazil

Full list of author information is available at the end of the article

\section{Results}

Of the 125 enrolled patients, 62 were assigned to GDTgroup and 63 to the usual-care group. There was no difference between groups regarding the amount of fluids received during 8 hours $(1345 \mathrm{~mL}$ [1042-1771] vs. 1100 $\mathrm{mL}$ [780-1388], $\mathrm{p}=0.151)$ of intervention and during 24 hours (2021 mL [1527-2844] vs. $2010 \mathrm{~mL}$ [17472410], $\mathrm{p}=0.372$ ). Patients in the GDT-group were more likely to receive dobutamine (37[66.1\%] vs. 12 [23.1\%], $\mathrm{p}<0.0001)$. At 30 days after randomization, the composite endpoint occurred in $25.8 \%$ in the GDT group and in $22.2 \%$ in the usual-care group ( $\mathrm{p}=0.639)$. There was no significant difference in blood transfusion requirements, in-hospital mortality, duration of organ support, or length of hospital stay.

\section{Conclusions}

In surgical critically ill patients admitted to the ICU after major abdominal oncology surgery, a GDT protocol did not reduce the incidence of major postoperative complications at 30 days. Also, the GDT protocol was associated with an overuse of inotropic agents. (ClinicalTrials.gov number, NCT 01946269.)

\section{Conflict of interest}

No conflict of interest to disclose

\section{Authors' details}

${ }^{1}$ Instituto do Câncer do Estado de São Paulo, Anesthesia and Critical Care, São Paulo, Brazil. 'Friedrich-Schiller University, Jena, Germany.

Published: 1 October 2015

\section{Reference}

1. Pearse RM, Harrison DA, MacDonald N, Gillies MA, Blunt M, Ackland G, Grocott MP, Ahern A, Griggs K, Scott R, Hinds C, Rowan K, OPTIMISE Study Group: Effect of a perioperative, cardiac output-guided hemodynamic therapy algorithm on outcomes following major gastrointestinal surgery: a randomized clinical trial and systematic review. JAMA 2014, 311(21):2181-90, Jun 4.

\section{SpringerOpen ${ }^{\circ}$}

C 2015 Gerent et al.; This is an Open Access article distributed under the terms of the Creative Commons Attribution License (http:// creativecommons.org/licenses/by/4.0), which permits unrestricted use, distribution, and reproduction in any medium, provided the original work is properly cited. 
doi:10.1186/2197-425X-3-S1-A819

Cite this article as: Gerent et al:: Goal-directed therapy in cancer surgery:

a randomised and controlled trial (GRICS II). Intensive Care Medicine

Experimental 2015 3(Suppl 1):A819.

Submit your manuscript to a SpringerOpen ${ }^{\circ}$ journal and benefit from:

- Convenient online submission

- Rigorous peer review

- Immediate publication on acceptance

- Open access: articles freely available online

- High visibility within the field

- Retaining the copyright to your article

Submit your next manuscript at $\gg$ springeropen.com 